\title{
Temperature studies of Urbach absorption edge in implanted $\mathrm{Cu}_{6} \mathrm{PS}_{5} \mathrm{Br}$ crystals
}

\author{
${ }^{1}$ Studenyak I.P., ${ }^{1}$ Izai V.Yu., ${ }^{1}$ Panko V.V., ${ }^{2}$ Kúš P. and ${ }^{2}$ Plecenik A. \\ ${ }^{1}$ Uzhhorod National University, 46 Pidhirna St., 88000 Uzhhorod, \\ Ukraine, e-mail: studenyak@dr.com \\ ${ }^{2}$ Comenius University, Mlynska Dolina, 84248 Bratislava, Slovakia
}

Received: 30.06 .2010

\begin{abstract}
$\mathrm{Cu}_{6} \mathrm{PS}_{5} \mathrm{Br}$ crystals grown with a chemical vapour transport technique are implanted with sulphur ions. Optical absorption edge for the implanted crystals is studied in the temperature range of 77-320 K. Temperature dependences of the optical pseudogap and the Urbach energy are analysed. The parameters of exciton-phonon interaction resulting from the Urbach behaviour of the optical absorption edge are determined. Ordering-disordering processes in $\mathrm{Cu}_{6} \mathrm{PS}_{5} \mathrm{Br}$ crystals induced by the ion implantation are studied.
\end{abstract}

Keywords: superionic conductors, implantation, phase transitions, Urbach absorption edge, structural disorder

PACS: $78.40 . \mathrm{Ha} ; 77.80 . \mathrm{Bh}$

UDC: 535.343 .2

\section{Introduction}

$\mathrm{Cu}_{6} \mathrm{PS}_{5} \mathrm{Br}$ crystals belong to the family of compounds with an argyrodite structure [1]. They are characterised by high concentration of disordered vacancies and manifest both superionic and ferroelastic properties. High ionic conductivity at the room temperature [2, 3] stipulates different possibilities for their practical applications as solid electrolyte sources of energy, sensors, and highly efficient capacitors.

$\mathrm{Cu}_{6} \mathrm{PS}_{5} \mathrm{Br}$ crystals belong to the cubic syngony (the space group $F \overline{4} 3 m$ ) at the room temperature and two phase transitions (PTs) occur at lower temperatures: a ferroelastic one at $T_{\mathrm{II}}=(268 \pm 2) \mathrm{K}$ and a superionic one at $T_{\mathrm{I}}=(166-180) \mathrm{K}$ [2]. Below the ferroelastic $\mathrm{PT}$ temperature, $\mathrm{Cu}_{6} \mathrm{PS}_{5} \mathrm{Br}$ crystals are monoclinic (the space group $C c$ ), while the superionic PT reveals some features of an isostructural transformation [4]. Anomalous behaviours of the calorimetric, acoustic and optical properties have been revealed in the region of the PTs [5-8]. The studies of the optical absorption edge in $\mathrm{Cu}_{6} \mathrm{PS}_{5} \mathrm{Br}$ have shown the existence of excitons below the superionic PT temperature, which undergo considerable changes with increasing temperature. The PT into superionic state results not only in variations of the exciton structure, but also in appearance of exponential regions at the 
long-wavelength absorption edge. The temperature behaviour of those exponential regions at $T>T_{\mathrm{I}}$ is known to be described by the empirical Urbach rule [8].

The present work is aimed at the studies of influence of ion implantation on the Urbach absorption edge in superionic $\mathrm{Cu}_{6} \mathrm{PS}_{5} \mathrm{Br}$ conductors and the role of orderingdisordering processes occurring in the crystal lattice in the formation of the absorption edge.

\section{Experimental}

Single $\mathrm{Cu}_{6} \mathrm{PS}_{5} \mathrm{Br}$ crystals were grown using a chemical vapour transport technique [2]. A standard experimental set-up with magnetic separation was used for the implantation. The angle of incidence was equal to $10^{\circ}$ and the sulphur ion energy was $150 \mathrm{keV}$. The implantation of the $\mathrm{Cu}_{6} \mathrm{PS}_{5} \mathrm{Br}$ crystals was performed using a ${ }^{32} \mathrm{~S}^{+}$isotope obtained from a sulphur powder heated above $400^{\circ} \mathrm{C}$ and delivered in the gaseous state to the ion source.

Spectral dependences of the absorption coefficient $\alpha$ were studied in the temperature range of $77-320 \mathrm{~K}$. The samples prepared for the transmittance and reflectance measurements were oriented at the room temperature while staying in their cubic phase. The linear absorption coefficient $\alpha$ as a function of transmittance, $T_{t r}$, and the reflectance of the surface, $R$, were calculated using the well-known formula which takes multiple internal reflections of light into account:

$$
\alpha=\frac{1}{d} \ln \left\{\frac{(1-R)^{2}}{2 T_{t r}}+\sqrt{\left[\frac{(1-R)^{2}}{2 T_{t r}}\right]^{2}+R^{2}},\right.
$$

with $d$ denoting the thickness of a plane-parallel sample. The experimental setup and the working technique have been described elsewhere (see, e.g., [2]). The relative error $\Delta \alpha / \alpha$ for determining the absorption coefficient does not exceed $10 \%$ at the conditions given by $0.3 \leq \alpha d \leq 3[9]$.

\section{Results and discussion}

The temperature studies of the optical absorption edge have shown that, like in the case of unimplanted $\mathrm{Cu}_{6} \mathrm{PS}_{5} \mathrm{Br}$ crystals, the shape of the absorption edge of the implanted crystals is exponential and follows the Urbach rule [10]:

$$
\alpha(h v, T)=\alpha_{0} \exp \left[\frac{\sigma\left(h v-E_{0}\right)}{k T}\right]=\alpha_{0} \exp \left[\frac{h v-E_{0}}{E_{U}(T)}\right],
$$

where $E_{U}$ is the Urbach energy, $\sigma$ the slope parameter of the absorption edge, $\alpha_{0}$ and $E_{0}$ the coordinates of the convergence point of the Urbach bundle, $k$ the Boltzmann constant, $T$ the temperature, and $h v$ the photon energy. As an example, Fig. 1 presents the spectral dependences of the absorption coefficient at different temperatures for the case of $\mathrm{Cu}_{6} \mathrm{PS}_{5} \mathrm{Br}$ crystal implanted with the fluence of $1 \times 10^{15}$ ions $/ \mathrm{cm}^{2}$. Similar Urbach bundles have been observed for all of the implanted crystals. The coordinates $\alpha_{0}$ and $E_{0}$ of the 
convergence point of the Urbach bundle for the unimplanted crystal and the crystals implanted with different fluences are gathered in Table 1. It should be noticed that the coordinates $\alpha_{0}$ and $E_{0}$ of the convergence point remain unchanged in the region of the secondorder structural PT (i.e., near the temperature point $T=T_{\text {II }}$ ).



Fig. 1. Spectral dependences of Urbach absorption edge obtained at different temperatures for the $\mathrm{Cu}_{6} \mathrm{PS}_{5} \mathrm{Br}$ crystal implanted with the fluence of $1 \times 10^{15} \mathrm{ions} / \mathrm{cm}^{2}: 1-200,2-250,3-280,4-300$, and $5-320 \mathrm{~K}$. The insert shows temperature dependence of the slope parameter $\sigma$.

Table1. Parameters of the Urbach absorption edge, parameters of the EPI and the PT temperatures for the unimplanted and implanted $\mathrm{Cu}_{6} \mathrm{PS}_{5} \mathrm{Br}$ crystals at $T>T_{\mathrm{II}}$. The $\alpha_{0}, E_{0}$ and $E_{g}^{*}$, and $E_{U}$ values are determined with the errors of $\pm 3 \times 10^{5} \mathrm{~cm}^{-1}, \pm 5 \times 10^{-4} \mathrm{eV}$, and $\pm 2 \times 10^{-4} \mathrm{eV}$, respectively.

\begin{tabular}{|c|c|c|c|c|c|c|}
\hline Crystal & $\begin{array}{c}\text { Unim- } \\
\text { planted }\end{array}$ & $\begin{array}{c}1 \times 10^{11} \\
\text { ions } / \mathrm{cm}^{2}\end{array}$ & $\begin{array}{c}1 \times 10^{12} \\
\text { ions } / \mathrm{cm}^{2}\end{array}$ & $\begin{array}{c}1 \times 10^{13} \\
\text { ions } / \mathrm{cm}^{2}\end{array}$ & $\begin{array}{c}1 \times 10^{14} \\
\text { ions } / \mathrm{cm}^{2}\end{array}$ & $\begin{array}{c}1 \times 10^{15} \\
\text { ions } / \mathrm{cm}^{2}\end{array}$ \\
\hline $\begin{array}{c}E_{g}^{*}(300 \mathrm{~K}) \\
(\mathrm{eV})\end{array}$ & 2.275 & 2.278 & 2.285 & 2.292 & 2.300 & 2.306 \\
\hline $\begin{array}{c}E_{U}(300 \mathrm{~K}) \\
(\mathrm{meV})\end{array}$ & 56.3 & 47.0 & 46.0 & 48.6 & 48.8 & 51.3 \\
\hline$\alpha_{0}\left(\mathrm{~cm}^{-1}\right)$ & $3.7 \times 10^{5}$ & $3.3 \times 10^{5}$ & $3.1 \times 10^{5}$ & $3.0 \times 10^{5}$ & $3.5 \times 10^{5}$ & $3.1 \times 10^{5}$ \\
\hline$E_{0}(\mathrm{eV})$ & 2.609 & 2.548 & 2.550 & 2.573 & 2.585 & 2.601 \\
\hline$\sigma_{0}$ & 0.664 & 0.818 & 0.812 & 0.755 & 0.779 & 0.745 \\
\hline$\hbar \omega_{p}(\mathrm{meV})$ & 62.6 & 65.5 & 62.4 & 60.5 & 64.4 & 64.9 \\
\hline$\theta_{E}(\mathrm{~K})$ & 726 & 760 & 724 & 702 & 747 & 753 \\
\hline$\left(E_{U}\right)_{0}(\mathrm{meV})$ & 47.2 & 40.1 & 38.4 & 40.0 & 41.3 & 43.8 \\
\hline$\left(E_{U}\right)_{1}(\mathrm{meV})$ & 94.1 & 79.8 & 76.9 & 80.0 & 82.6 & 84.5 \\
\hline$E_{g}^{*}(0)(\mathrm{eV})$ & 2.323 & 2.320 & 2.331 & 2.339 & 2.345 & 2.352 \\
\hline$S_{g}^{*}$ & 7.84 & 7.55 & 7.48 & 7.25 & 7.63 & 7.93 \\
\hline$T_{\mathrm{II}}(\mathrm{K})$ & $265.6 \pm 0.5$ & $267.6 \pm 0.5$ & $269.4 \pm 0.5$ & $269.0 \pm 0.5$ & $268.5 \pm 0.5$ & $268.5 \pm 0.5$ \\
\hline
\end{tabular}


Following from our analysis of the Urbach absorption edge, the optical pseudogap $E_{g}^{*}$ and the Urbach energy $E_{U}$ have been obtained (see Fig. 2). Here the $E_{g}^{*}$ parameter means the absorption edge energy position taken at a fixed value of the absorption coefficient ( $\alpha=10^{3} \mathrm{~cm}^{-1}$ in our case), while $E_{U}$ is the energy width of the exponential absorption edge. It has been revealed that the optical pseudogap $E_{g}^{*}$ increases as a result of ion implantation. On the other hand, the Urbach energy $E_{U}$ decreases for the fluence values less than $1 \times 10^{12}$ ions $/ \mathrm{cm}^{2}$ and increases if the latter exceed $1 \times 10^{12}$ ions $/ \mathrm{cm}^{2}$. This testifies that the small fluences initiate some crystal lattice ordering processes, while in case of the fluences larger than $1 \times 10^{12}$ ions $/ \mathrm{cm}^{2}$ we deal with lattice disordering.

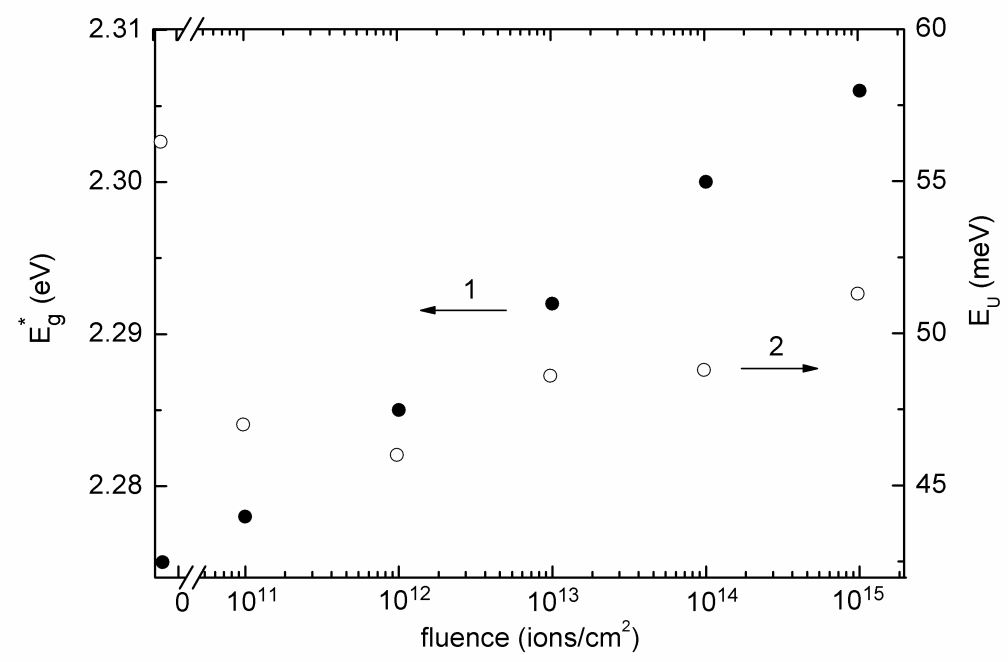

Fig. 2. Dependences of optical pseudogap $E_{g}^{*}(1)$ and Urbach energy $E_{U}$ (2) on the fluence value for the implanted $\mathrm{Cu}_{6} \mathrm{PS}_{5} \mathrm{Br}$ crystals. The sizes of the symbols of experimental data points exceed the error bars which are $\pm 5 \times 10^{-4} \mathrm{eV}$ for $E_{g}^{*}$ and $\pm 2 \times 10^{-4} \mathrm{eV}$ for $E_{U}$.

Exponential shape of a long-wavelength tail of the absorption edge is usually attributed to an exciton-phonon interaction (EPI) [11]. In the whole temperature interval under study, both the implanted and unimplanted $\mathrm{Cu}_{6} \mathrm{PS}_{5} \mathrm{Br}$ crystals manifest the temperature dependences of the slope parameter $\sigma$ described by the Mahr relation [11]:

$$
\sigma(T)=\sigma_{0}\left(\frac{2 k T}{\hbar \omega_{p}}\right) \tanh \left(\frac{\hbar \omega_{p}}{2 k T}\right),
$$

where $\sigma_{0}$ is a constant independent of temperature, which is related to the EPI constant $g$ $\left(\sigma_{0}=2 / 3 g\right)$, and $\hbar \omega_{p}$ denotes an average effective phonon energy in a single-oscillator model describing the EPI [11]. An example of such dependence is presented in the insert of Fig. 1. It is worthwhile that the inequality $\sigma_{0}<1$ indicating a strong EPI (see [12]) holds true for the both implanted and unimplanted $\mathrm{Cu}_{6} \mathrm{PS}_{5} \mathrm{Br}$ crystals. The values of the 
effective phonon energy $\hbar \omega_{p}$ and the $\sigma_{0}$ parameter are given in Table 1 . It is seen that both the $\sigma_{0}$ and $\hbar \omega_{p}$ parameters first increase with increasing fluence (by $23 \%$ and $5 \%$, respectively), then decrease (for the fluence values less than $1 \times 10^{13} \mathrm{ions} / \mathrm{cm}^{2}$ ) and eventually increase weakly (for the fluences exceeding $1 \times 10^{13} \mathrm{ions} / \mathrm{cm}^{2}$ ).

Among numerous theoretical treatments of the Urbach rule, a model of self-trapped exciton by Sumi and Toyozava (ST) [13] and a microelectric-field theory (a so-called internal Franz-Keldysh effect) by Dow and Redfield (DR) [14] are the most often cited. In our earlier work [2] we have shown that the mechanism of EPI in $\mathrm{Cu}_{6} \mathrm{PS}_{5} \mathrm{Br}$ crystals is well explained in the framework of the DR theory. According to the latter, broadening of excitonic maxima that occurs with increasing temperature and a resulting exponential absorption edge are associated with the interaction of excitons with microelectric fields generated by LO phonons [14]. In order to check whether the DR theory could also describe the EPI in the implanted $\mathrm{Cu}_{6} \mathrm{PS}_{5} \mathrm{Br}$ crystal, we have applied the procedure suggested in the study [15]. Here influence of the external electric field $F_{e}$ causing the internal Franz-Keldysh effect is replaced by the root-mean square value of the phononinduced internal electric field $F_{p}$, thus leading to the expression

$$
E_{g}^{*} \tanh \left(\frac{\hbar \omega_{p}}{2 k T}\right)=E_{g}^{*}(0)-E_{0}\left[1-\tanh \left(\frac{\hbar \omega_{p}}{2 k T}\right)\right],
$$

where $E_{g}^{*}(0)$ is the band gap at zero temperature. A linear relation between $E_{g}^{*} \tanh \left(\hbar \omega_{p} / 2 k T\right)$ and $\left[1-\tanh \left(\hbar \omega_{p} / 2 k T\right)\right\rfloor$ depicted in Fig. 3 supports a qualitative agreement between the DR theory and the absorption processes in these crystals.

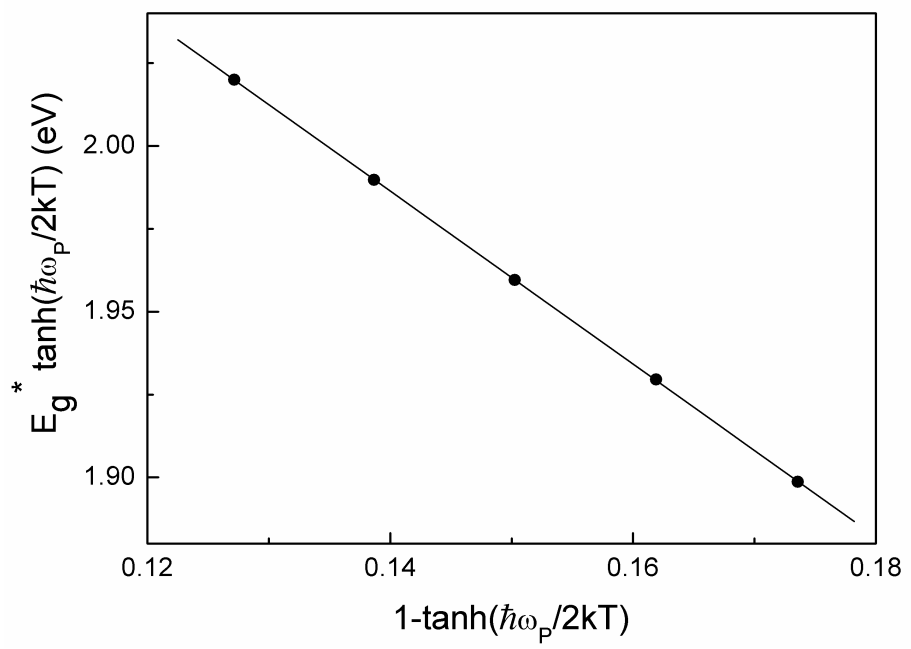

Fig. 3. Illustration of linear relation between the parameters $E_{g}^{*} \tanh \left(\hbar \omega_{p} / 2 k T\right)$ and $\left[1-\tanh \left(\hbar \omega_{p} / 2 k T\right)\right]$ taking place for the $\mathrm{Cu}_{6} \mathrm{PS}_{5} \mathrm{Br}$ crystal implanted with the fluence of $1 \times 10^{15}$ ions $/ \mathrm{cm}^{2}\left(T>T_{\text {II }}\right)$. 
Temperature dependences of the optical pseudogap $E_{g}^{*}$ and the Urbach energy $E_{U}$ for the $\mathrm{Cu}_{6} \mathrm{PS}_{5} \mathrm{Br}$ crystal implanted by sulphur ions with the fluence of $1 \times 10^{15}$ ions $/ \mathrm{cm}^{2}$ are shown in Fig. 4. We are to emphasise that, due to the EPI, the temperature behaviour of $E_{g}^{*}$ seen in Fig. 4 can be described in frame of the Einstein model by the relation [16]

$$
E_{g}^{*}(T)=E_{g}^{*}(0)-S_{g}^{*} k \theta_{E}\left[\frac{1}{\exp \left(\theta_{E} / T\right)-1}\right],
$$

where $E_{g}^{*}(0)$ is the energy gap at $0 \mathrm{~K}, S_{g}^{*}$ a dimensionless constant, and $\theta_{E}$ the Einstein temperature corresponding to the average frequency of phonon excitations of a system of non-coupled oscillators. The calculations performed by us prove that the experimental $E_{g}^{*}$ values are well described by Eq. (5). The $E_{g}^{*}(0), S_{g}^{*}$ and $\theta_{E}$ parameters obtained for the unimplanted and implanted crystals are given in Table 1, whereas a solid line shown in Fig. 4 represents the temperature dependence of the optical pseudogap $E_{g}^{*}$ calculated basing on Eq. (5) for the $\mathrm{Cu}_{6} \mathrm{PS}_{5} \mathrm{Br}$ crystal implanted with the fluence of $1 \times 10^{15}$ ions $/ \mathrm{cm}^{2}$.

It is well known that the Urbach energy $E_{U}$ in frame of the Einstein model is described as [17]

$$
\left(E_{U}\right)=\left(E_{U}\right)_{0}+\left(E_{U}\right)_{1}\left[\frac{1}{\exp \left(\theta_{E} / T\right)-1}\right],
$$

where $\left(E_{U}\right)_{0}$ and $\left(E_{U}\right)_{1}$ are constants. The values of $\left(E_{U}\right)_{0}$ and $\left(E_{U}\right)_{1}$ obtained by fitting Eq. (6) to the experimental temperature dependences of $E_{U}$ for the unimplanted and implanted crystals are also listed in Table 1. The temperature dependence of the Urbach energy $E_{U}$ for the $\mathrm{Cu}_{6} \mathrm{PS}_{5} \mathrm{Br}$ crystal implanted with the fluence of $1 \times 10^{15} \mathrm{ions} / \mathrm{cm}^{2}$ is shown in Fig. 4 as a dashed line.

In [18] it has been shown that both the temperature-related effect and the structural disordering affect the shape of the Urbach absorption edge, so that the Urbach energy $E_{U}$ is described by the relation

$$
E_{U}=\left(E_{U}\right)_{T}+\left(E_{U}\right)_{X}=\left(E_{U}\right)_{T}+\left(E_{U}\right)_{X, s t a t}+\left(E_{U}\right)_{X, d y n},
$$

where $\left(E_{U}\right)_{T}$ and $\left(E_{U}\right)_{X}$ are respectively the temperature-related and structural disordering contributions to $E_{U}$, while $\left(E_{U}\right)_{X, \text { stat }}$ and $\left(E_{U}\right)_{X, d y n}$ imply the contributions of static structural disordering and dynamic structural disordering to $\left(E_{U}\right)_{X}$, respectively.

The static structural disordering $\left(E_{U}\right)_{X \text {,stat }}$ in the $\mathrm{Cu}_{6} \mathrm{PS}_{5} \mathrm{Br}$ crystal is caused by structural imperfection due to high concentration of disordered copper vacancies, while the dynamic disordering $\left(E_{U}\right)_{X, d y n}$ is concerned with intense motion of mobile copper ions participating to the ion transport, which is responsible for ionic conductivity [8]. One 
should notice that the first term in the right-hand side of Eq. (6) represents the static structural disordering and the second one - the temperature-related types of disordering. These are the temperature disordering due to thermal lattice vibrations and the dynamic structural disordering linked with the presence of mobile ions in superionic conductors.

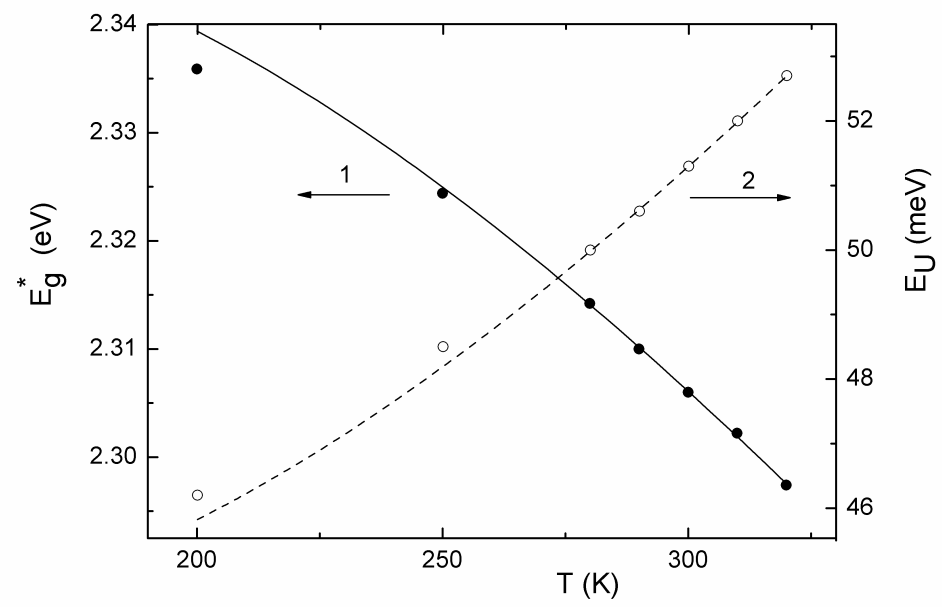

Fig. 4. Temperature dependences of optical pseudogap $E_{g}^{*}$ (curve 1) and Urbach energy $E_{U}$ (curve 2) for the $\mathrm{Cu}_{6} \mathrm{PS}_{5} \mathrm{Br}$ crystal implanted with the fluence of $1 \times 10^{15}$ ions $/ \mathrm{cm}^{2}$ : circles correspond to the experiment and curves to the calculations. Solid and dashed lines are obtained by using Eqs. (5) and (6) for fitting the experimental data, with the parameters listed in Table 1. The sizes of the symbols of experimental data points exceed the error bars $\left( \pm 5 \times 10^{-4} \mathrm{eV}\right.$ for $E_{g}^{*}$ and $\pm 2 \times 10^{-4} \mathrm{eV}$ for $\left.E_{U}\right)$.

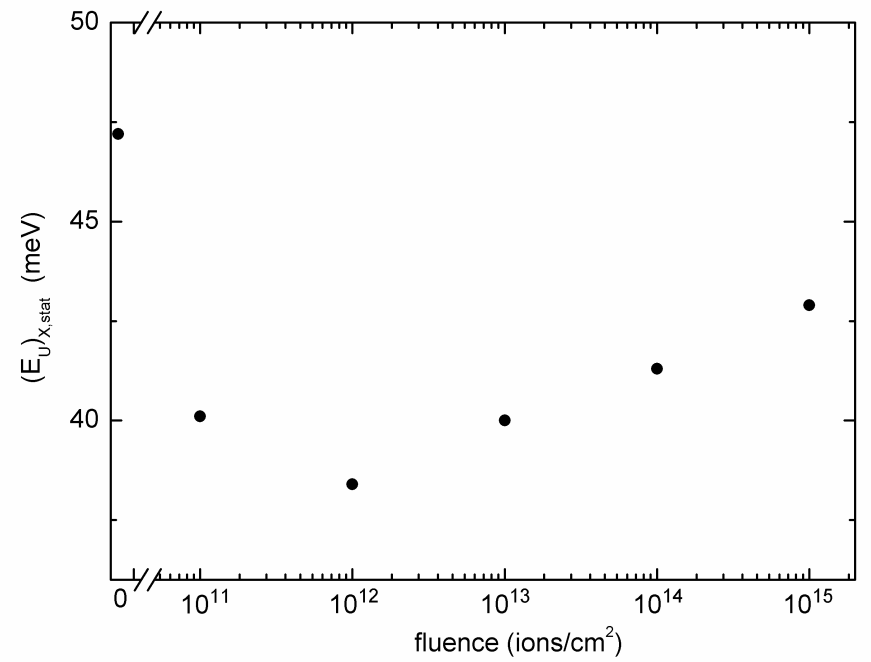

Fig. 5. Dependence of contribution of the static structural disordering $\left(E_{U}\right)_{X \text {,stat }}$ to the Urbach energy $E_{U}$ on the fluence value for the implanted $\mathrm{Cu}_{6} \mathrm{PS}_{5} \mathrm{Br}$ crystals. 
We have evaluated contribution of the static structural disordering to the Urbach energy $E_{U}$ for the implanted $\mathrm{Cu}_{6} \mathrm{PS}_{5} \mathrm{Br}$ crystals. As one can see from Fig. 5, the absolute value of that contribution decreases initially with increasing fluence, reaches a minimum at the fluence of $1 \times 10^{12} \mathrm{ions} / \mathrm{cm}^{2}$, and then increases again. At the fluence of $1 \times 10^{15}$ ions $/ \mathrm{cm}^{2}$ it amounts to 93 per cent of the absolute value of contribution of the static structural disordering for the unimplanted crystal (see Fig. 5 and Table 1).

\section{Conclusions}

$\mathrm{Cu}_{6} \mathrm{PS}_{5} \mathrm{Br}$ single crystals grown with the chemical vapour transport technique have been implanted with different fluences of $150 \mathrm{keV}^{32} \mathrm{~S}^{+}$ions. The optical absorption edges for the both unimplanted and implanted $\mathrm{Cu}_{6} \mathrm{PS}_{5} \mathrm{Br}$ crystals have exponential shapes, following the well-known Urbach rule. The temperature behaviour of the Urbach absorption edge is determined by the EPI, which is strong enough in both the unimplanted and implanted crystals. The temperature dependences of the optical pseudogap $E_{g}^{*}$ and the Urbach energy $E_{U}$ are successfully obtained. They are well described by the theoretical curves calculated in the framework of the Einstein model. We have also shown that the ordering processes take place in the crystal lattice for the fluences less than $1 \times 10^{12}$ ions $/ \mathrm{cm}^{2}$, while the fluence values larger than $1 \times 10^{12}$ ions $/ \mathrm{cm}^{2}$ cause disordering of the lattice.

\section{References}

1. Kuhs W F, Nitsche R and Scheunemann K, 1978. The crystal structure of $\mathrm{Cu}_{6} \mathrm{PS}_{5} \mathrm{Br}$, a new superionic conductor. Acta Cryst. B. 34: 64-70.

2. Studenyak I P, Kranjcec M, Kovacs Gy S, Panko V V, Desnica I D, Slivka A G and Guranich P P, 1999. The effect of temperature and pressure on the optical absorption edge in $\mathrm{Cu}_{6} \mathrm{PS}_{5} \mathrm{X}(\mathrm{X}=\mathrm{Cl}, \mathrm{Br}, \mathrm{I})$ crystals. J. Phys. Chem. Solids. 60: 1897-1904.

3. Beeken R B, Garbe $J$ J and Petersen N R, 2003. Cation mobility in the $\mathrm{Cu}_{6} \mathrm{PS}_{5} \mathrm{X}$ ( $\mathrm{X}=\mathrm{Cl}, \mathrm{Br}, \mathrm{I}$ ) argyrodites. J. Phys. Chem. Solids. 64: 1261-1264.

4. Haznar A, Pietraszko A and Studenyak I P, 1999. X-ray study of the superionic phase transition in $\mathrm{Cu}_{6} \mathrm{PS}_{5} \mathrm{Br}$. Solid State Ionics. 119: 31-36.

5. Fiechter $\mathrm{S}$ and Gmelin E, 1985. Thermochemical data of argyrodite-type ionic conductors: $\mathrm{Cu}_{6} \mathrm{PS}_{5} \mathrm{Hal}(\mathrm{Hal}=\mathrm{Cl}, \mathrm{Br}, \mathrm{I})$. Thermochimica Acta. 85: 155-158.

6. Samulionis V, Banys J, Vysochanskii Y and Studenyak I, 2006. Investigation of ultrasonic and acoustoelectric properties of ferroelectric-semiconductor crystals. Ferroelectrics. 336: 29-38.

7. Girnyk I, Kaynts D, Krupych O, Martunyuk-Lototska I and Vlokh R, 2003. X,Tphase diagram of the $\mathrm{Cu}_{6} \mathrm{PS}_{5} \mathrm{I}_{\mathrm{x}} \mathrm{Br}_{1-\mathrm{x}}$ mixed crystals. Optical, dilatation and ultrasonic velocity studies. Ukr. J. Phys. Opt. 4: 165-179.

8. Studenyak I P, Kranjčec M and Kurik M V, 2006. Urbach rule and disordering processes in $\mathrm{Cu}_{6} \mathrm{P}\left(\mathrm{S}_{1-\mathrm{x}} \mathrm{Se}_{\mathrm{x}}\right)_{5} \mathrm{Br}_{1-\mathrm{y}} \mathrm{I}_{\mathrm{y}}$ superionic conductors. J. Phys. Chem. Solids. 67: 807817. 
9. Oswald F, 1959. Zur meßgenauigkeit bei der bestimmung der absorptionskonstanten von halbleitern im infraroten spektralbereich. Optik. 16: 527-537.

10. Urbach F, 1953. The long-wavelength edge of photographic sensitivity and electronic absorption of solids. Phys. Rev. 92: 1324-1326.

11. Kurik M V, 1971. Urbach rule (Review). Phys. Stat. Sol. (a). 8: 9-30.

12. Sumi $\mathrm{H}$ and Sumi A, 1987. The Urbach-Martiensen rule revisited. J. Phys. Soc. Japan. 56: 2211-2220.

13. Sumi H and Toyozawa $Y, 1971$. Urbach-Martiensen rule and exciton trapped momentarily by lattice vibrations. J. Phys. Soc. Japan. 31: 342-357.

14. Dow J D and Redfield D, 1972. Toward a unified theory of Urbach's rule and exponential absorption edge. Phys. Rev. B. 5: 594-610.

15. Samuel L, Brada Y, Burger A and Roth M, 1987. Urbach rule in mixed single crystals of $\mathrm{Zn}_{\mathrm{x}} \mathrm{Cd}_{1-\mathrm{x}} \mathrm{Se}$. Phys. Rev. B. 36: 1168-1173.

16. Beaudoin M, DeVries A J G, Johnson S R, Laman H and Tiedje T, 1997. Optical absorption edge of semi-insulating GaAs and InP at high temperatures. Appl. Phys. Lett. 70: 3540-3542.

17. Yang Z, Homewood K P, Finney M S, Harry M A and Reeson K J, 1995. Optical absorption study of ion beam synthesised polycrystalline semiconducting $\mathrm{FeSi}_{2}$. J. Appl. Phys. 78: 1958-1963.

18. Cody G D, Tiedje T, Abeles B, Brooks B and Goldstein Y, 1981. Disorder and the optical-absorption edge of hydrogenated amorphus silicon. Phys. Rev. Lett. 47: 1480-1483.

Studenyak I.P., Izai V.Yu., Panko V.V., Kúš P. and Plecenik A. 2010. Temperature studies of Urbach absorption edge in implanted $\mathrm{Cu}_{6} \mathrm{PS}_{5} \mathrm{Br}$ crystals. Ukr.J.Phys.Opt. 11: 175-183.

Анотація. Кристали $\mathrm{Cu}_{6} P S_{5} B r$, вирощені методом газотранспортних реакиії $і$ імплантовані іонами сірки. Досліджений край оптичного поглинання імплантованих кристалів в температурному діапазоні 77-320 К. Проаналізовані температурні залежності забороненої зони і енергії Урбаха. На основі урбахівської поведінки краю оптичного поглинання визначені параметри екситон-фоннонної взаємодії. $B$ кристалах $\mathrm{Cu}_{6} P \mathrm{~S}_{5} \mathrm{Br}$ досліджений процес впорядкування- розупорядкування, індукований іонною імплантацією. 